\title{
Primary auriculotemporal neuralgia. Case report
}

\author{
Neuralgia do aurículotemporal primária. Relato de caso
}

Maurício Kosminsky ${ }^{1}$, Michele Gomes do Nascimento

DOI 10.5935/1806-0013.20150064

\section{ABSTRACT}

BACKGROUND AND OBJECTIVES: Auriculotemporal neuralgia is an uncommon condition. Symptoms are brief severe pain attacks, especially in the temporal region. Although many cranial neuralgias are related to nervous compression, they may be present without identifiable etiologic factors. This study aimed at describing a case of primary auriculotemporal neuralgia and respective therapeutic approach.

CASE REPORT: Male patient, 72 years old, presented for assistance reporting severe pain in left temporal region, described as shock and of very short duration. After clinical evaluation and imaging exams, no significant changes were detected. Patient has satisfactorily responded to carbamazepine.

CONCLUSION: This case shows that auriculotemporal neuralgia has clinical presentation similar to other neuralgias. Diagnosis is primarily obtained by pain characteristics evaluation and exclusion of possible secondary causes.

Keywords: Auriculotemporal nerve, Auriculotemporal neuralgia, Neuropathic pain.

\section{RESUMO}

JUSTIFICATIVA E OBJETIVOS: A neuralgia do aurículotemporal é uma condição rara. Os sintomas consistem em ataques de dor intensa, de curta duração, sobretudo na regiáo temporal. Embora muitos casos de neuralgias cranianas sejam relacionados à compressão nervosa, podem ocorrer sem fatores etiológicos identificáveis. O objetivo deste estudo foi descrever um caso de neuralgia auriculotemporal primária e respectiva conduta terapêutica.

RELATO DO CASO: Paciente do gênero masculino, 72 anos, compareceu para atendimento relatando dor intensa em regiáo temporal esquerda, descrita como choque, de curtíssima duração. Após avaliação clínica e exames de imagens, não foram detectadas alteraçóes significativas. $\mathrm{O}$ paciente respondeu de forma satisfatória à carbamazepina.

\footnotetext{
1. Universidade de Pernambuco, Recife, PE, Brasil.

Submitted in July 16, 2015.

Accepted for publication in October 23, 2015.

Conflict of interests: none - Sponsoring sources: none.

Correspondence to:

Michele Gomes do Nascimento

R. Artur Coutinho, 143 - Santo Amaro

50100-280Recife, PE, Brasil.

E-mail: michelepmpe@yahoo.com.br

(C) Sociedade Brasileira para o Estudo da Dor
}

CONCLUSÃO: O caso descrito mostra que a aurículotemporal possui apresentação clínica semelhante àquela de outras neuralgias. O diagnóstico é obtido principalmente pela análise das características da dor e exclusão de possíveis causas secundárias.

Descritores: Dor neuropática, Nervo aurículotemporal, Neuralgia do aurículotemporal.

\section{INTRODUCTION}

Neuropathic pain results from a primary nervous system injury or disorder, triggered by local trauma or systemic diseases and affecting peripheral or central nervous structures. Considering the symptom, orofacial neuropathic pain may be classified in two categories: episodic or continuous. Episodic neuropathic pain is characterized by pain paroxysms described as electric shock or twinge, similar to what happens with trigeminal neuralgia $(\mathrm{TN})^{1}$. Pain paroxysms are in general followed by remission periods, known as refractory periods. Pain may be classified in primary (classic) or secondary (symptomatic) and the difference between them is important for adequate diagnosis and management. While the vast majority of patients have brief, severe and paroxysmal pain, continuous pain may also be present ${ }^{2,3}$. Most common neuralgias are trigeminal, post-herpetic, glossopharyngeal and occipital. Less frequent are supraorbital and intermediate nerve neuralgia. These disorders may underlie infectious and/or inflammatory neurologic diseases, in addition to other primary headaches ${ }^{3}$.

The auriculotemporal nerve (n.AT) is a sensory branch originating from mandibular nerve posterior trunk. Due to its pathway, there is major risk for compression and irritation. Its nervous roots form a short trunk, which supplies several branches and innervates temporomandibular joint (TMJ), temporal region, pinna and external acoustic meatus. It conducts sympathetic fibers to the scalp and parasympathetic fibers to the parotid gland ${ }^{4}$. Anatomic relationship between n.AT and masticatory muscles, TMJ and surrounding vessels in the infra temporal fossa region, creates favorable conditions for compressive syndromes ${ }^{5,6}$.

Auriculotemporal neuralgia (NAT) is an uncommon condition. In a tertiary center, reported frequency was just $0.4 \%{ }^{7}$. It seems to be more prevalent in middle-aged females. Symptoms are excruciating pain attacks, especially in the temporal region. Pain in TMJ, parotid and ear, with irradiation to temporal region is also described and may be relieved by auriculotemporal nerve anesthetic block ${ }^{8,9}$. Although not having its own classification, the name epicranial neuralgias has been suggested, including neuralgias of other peripheral branch- 
es ${ }^{10,11}$, such as supraorbital, supratrochlear, nasal, greater and lesser occipital nerves ${ }^{12}$.

Although many cranial neuralgias are primary, other etiologic factors may be involved. Refractory cases or with paresthesia may indicate the presence of expansive injuries. Although mechanisms of such conditions are not totally explained, non-odontogenic toothache ${ }^{7}$, refractory facial pain ${ }^{8}$, as well as NAT secondary to synovial cyst in the condyle ${ }^{13}$ are reported by the literature.

This study aimed at reporting a case of NAT where underlying secondary factors were not found, and which has favorably responded to low dose of carbamazepine.

\section{CASE REPORT}

Male patient, 72 years old, who came for assistance complaining of severe left temporal region pain, described as shock. First crisis had been 5 years ago with spontaneous remission. Two months ago pain reappeared, with very short duration, with several episodes varying from 1 to 2 minutes. These episodes were repeated three to four times a day and did not wake up patient at night. At physical evaluation, no pain trigger-zone was found. Patient had controlled diabetes and referred having been submitted to prostatectomy due to cancer. Brain magnetic resonance was normal. Panoramic X-rays of jaws and computerized tomography of temporomandibular joints had not shown significant changes (Figures 1, 2 and 3). Diagnostic hypothesis was NAT. Carbamazepine (200mg) was prescribed during the first two days, continuing with $400 \mathrm{mg}$ for the following 15 days. In the first week using the drug, patient was revaluated and reported lower frequency of shocks ( 2 to 3 per day), which he defined as "pinching". In the following week, patient referred symptoms remission. Maintenance dose of $200 \mathrm{mg}$ was then kept and 4 months later there has been total symptoms control.

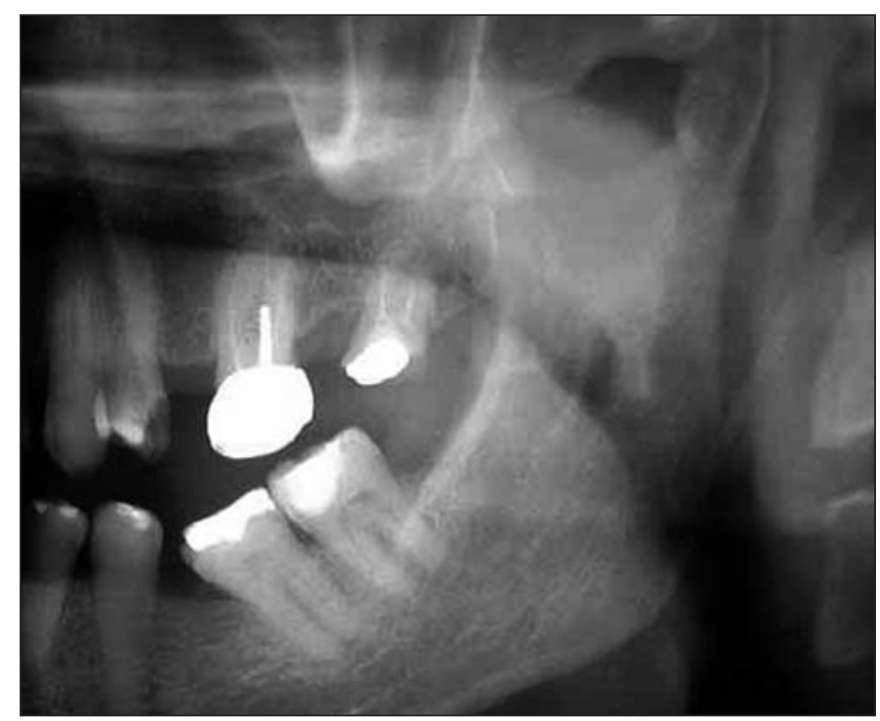

Figure 1. Panoramic X-rays approximate left side view There were no significant changes.

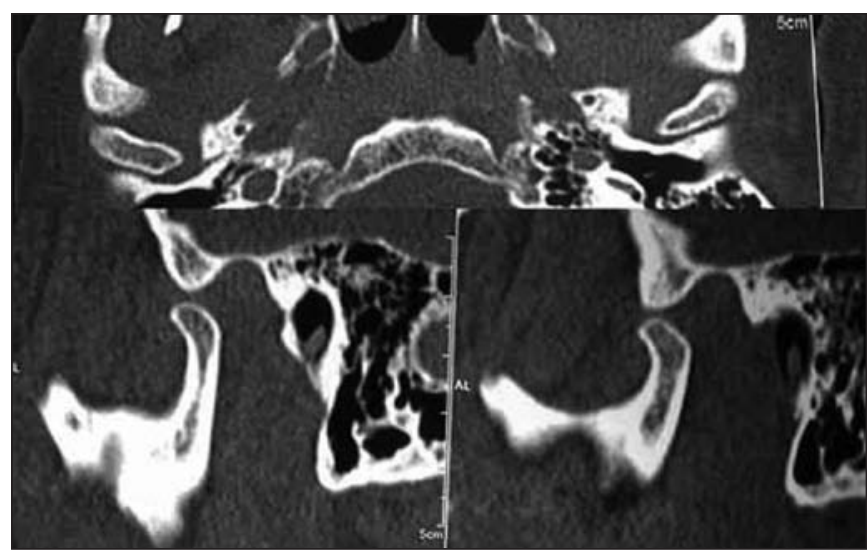

Figure 2. Computerized tomography of temporomandibular joint (open mouth)

There were no temporomandibular joints expansive injuries.

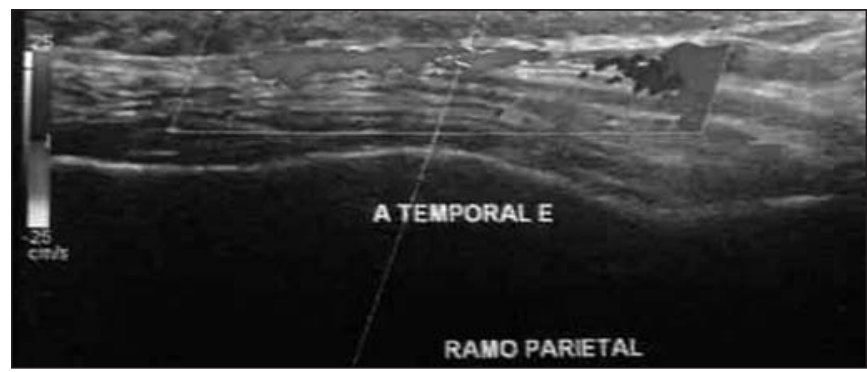

Figure 3. Ultrasound of left temporal region

\section{DISCUSSION}

Due to its rarity, the International Classification of Headache Disorders (ICHD-II) does not have a specific category for NAT, being it classified as "neuralgia of other terminal branches". Diagnostic criteria are: 1) Pain in the distribution of a trigeminal nerve peripheral branch, except nasociliary and supraorbital nerves; 2) Sensitivity on affected nerve; 3) Pain is eliminated with anesthetic block or nerve ablation ${ }^{11}$. In the new ICHD-III classification, however, this category was not included $^{10}$. Differential NAT diagnosis should be obtained to rule out other disorders, including temporomandibular disorders, toothache, continuous migraine, earache, trigeminal neuralgia, temporal arteritis, myofascial pain and atypical facial pain ${ }^{2-7}$.

Primary diagnosis of our patient was obtained by means of pain characteristics, such as location, quality, intensity, frequency and duration. Imaging exams (panoramic X-rays, TMJ tomography and temporal region ultrasound) were asked to exclude possible secondary causes of the disease. Masticatory muscles palpation has not shown relevant changes. For being a well located pain in temporal region without irradiation patterns, in shock, we have considered initial diagnosis of NAT.

In the period between 2004 and 2005, a total of 1500 patients were evaluated in a pain control tertiary center. Six cases of NAT were documented. All patients were females aged 
between 23 and 65 years. The interval between beginning of symptoms and diagnosis has varied from 1 month to 20 years. Pain was moderate to severe, located around the ear, and irradiating to condyle and temporal region in all patients. Pain was continuous in 5 cases and associated with stabbing-type exacerbation in three. One patient had pre-auricular triggerpoint.

One patient has reported this symptom triggered by gustatory stimulation causing diet limitations. Pain was unilateral, not involving the opposite side. For all patients, pain was triggered or worsened by pressure in the pre-auricular region or slightly above $i^{2}$. In our case, patient has referred beginning of symptoms two months ago, had severe, spontaneous and brief pain episodes which were repeated at few minutes intervals.

n.AT trunk has close anatomic relationship with condyle and TMJ capsule region, which may contribute to sensory disorders in this site. In several studied cases, nerve was in direct contact with the medial aspect of the capsule or of the neck of the condyle. Studies have not observed anatomic correspondences between right and left sides, so just one side can be affected. n.AT may also be in direct contact with lateral pterygoid muscle ${ }^{14}$. Findings support the hypothesis that the anatomic relationship between n.AT and condyle, articular fossa and lateral pterygoid muscle might be associated to its compression and irritation, thus contributing to neuropathic pain in its innervated regions ${ }^{15}$.

To investigate n.AT compression mechanism, Komarkitki et al. ${ }^{5}$ have studied the infratemporal fossa in 16 specimens and have found that the number of n.AT roots varied between 1 and 5. They have observed that, in variations where n.AT had 4 to 5 roots, there were complex connections. In five cases, lowest n.AT roots started in the inferior alveolar nerve instead of in the mandibular nerve. This study findings point to two major factors which may be involved with auriculotemporal nerve compression in its pathway inside the infratemporal fossa. The first is anatomic variation while the second is the presence of masticatory muscles disorder, especially lateral pterygoid muscle. According to the authors, even minor structural or functional changes may lead to painful syndromes. In fact, our patient complained of shock and unilateral pain in temporal region. However, there were no trigger-points related to jaw functional demands in this case. Pharmacological treatment is still the first line to control several neuralgias. It may be obtained with the association of classic analgesics and anticonvulsant or antidepressant drugs. In patients with classic trigeminal neuralgia, carbamazepine is considered the first choice drug. However, several adverse effects are associated to its use, among them skin erythema, negative effect on bone density, liver changes and pharmacological interaction. Oxcarbazepine may be used in patients nor responding to carbamazepine. Second line drugs are baclofen, lamotrigine, pregabalin and gabapentin ${ }^{16}$.

Anesthetic blocks, surgery and other procedures may be necessary for refractory cases ${ }^{3}$. Literature states that n.AT anesthetic block is diagnostic and therapeutic. It is performed with $0.5 \mathrm{~mL} 2 \%$ lidocaine without vasoconstrictor and dexamethasone $(2.5 \mathrm{mg} / 0,5 \mathrm{~mL})$, being described successful reports in symptoms control ${ }^{2,7,8}$. Anesthetic block induces immediate pain relief in patients with different types of headaches. In addition, its analgesic effect is longer as compared to anesthesia, so that patients have pain relief for weeks or even months. This prolonged anesthetic effect after peripheral block may be related to effect on central pain modulation. Anesthetic blocks are indicated for some primary headaches, secondary headaches and cranial neuralgias. One must take care with certain populations of patients, including pregnant women, elderly, those allergic to substances used, with history of previous vasovagal episodes and in use of anticoagulants. Described peripheral anesthetic blocks involve injections in greater and lesser occipital nerves, supratrochlear, supraorbital and auriculotemporal nerves ${ }^{17}$. Reported complications include pain, bleeding, infection an intravascular injection ${ }^{3}$. To investigate analgesic efficacy and tolerability to pharmacological treatment, 200 patients with classic trigeminal neuralgia (TN) were selected. Carbamazepine (CBZ) was prescribed for 100 individuals and oxcarbamazepine (OXC) was prescribed for the other 100 . Response to $\mathrm{CBZ}$ was found in $98 \%$, with mean dose of $600 \mathrm{mg}$ (200-1200), and response to OXC has been 94\%, with mean dose of $1200 \mathrm{mg}$ (600-1800). In a period of approximately 8.6 months, $27 \%$ of patients responding to CBZ had major adverse effects, being necessary to discontinue the drug or to decrease it to unsatisfactory levels. After 13 months, the same has happened with $18 \%$ of respondents to OXC. Among patients with good initial response, only 3 individuals using $\mathrm{CBZ}$ and 2 using $\mathrm{OXC}$ have developed late resistance. During the course of disease, paroxysms have worsened in 3\% of patients and their duration has increased $2 \%$. In a 7 -year period, no clinical sensory deficit manifestations were observed for all patients. Based on available evidences, CBZ or OXC are considered first therapeutic option $^{18,19}$.

In a retrospective study with 72 classic TN patients, CBZ was highly effective in $60.8 \%$ of cases in the long term with maintenance dose. Other drugs were used in more refractory cases, including gabapentin, which has relieved symptoms with mean duration of 18 months. Peripheral neurectomy was needed for $23 \%$ of patients ${ }^{20}$.

Considering our case report, where there were no secondary underlying etiologic factors, we decided for CBZ as first therapeutic option. In addition, although literature states that anesthetic block may be considered initial clinical decision, factors such as pain characteristics, patient's age and the possibility of response to conservative therapy were taken into consideration

\section{CONCLUSION}

This case shows that NAT has clinical presentation similar to that of other neuralgias. The diagnosis of this uncommon condition is primarily obtained by evaluating pain characteristics and by excluding possible secondary causes. 


\section{REFERENCES}

1. Benoliel R, Eliav E. Neuropathic orofacial pain. Oral Maxillofac Surg Clin North Am. 2008;20(2):237-54

2. Speciali JG, Gonçalves DA. Auriculotemporal neuralgia. Curr Pain Headache Rep. 2005;9(4):277-80

3. Gadient PM, Smith JH. The neuralgias: diagnosis and management. Curr Neurol Neurosci Rep. 2014;14(7):459.

4. Janis JE, Hatef DA, Ducic I, Ahmad J, Wong C, Hoxworth RE, et al. Anatomy of the auriculotemporal nerve: variations in its relationship to the superficial temporal artery and implications for the treatment of migraine headaches. Plast Reconstr Surg. 2010;125(5):1422-8

5. Komarnitki I, Andrzejczak-Sobocińska A, Tomczyk J, Deszczyńska K, Ciszek B. Clini$\mathrm{cal}$ anatomy of the auriculotemporal nerve in the area of the infratemporal fossa. Folia Morphol. 2012;71(3):187-93.

6. Dias GJ, Koh JM, Cornwall J. The origin of the auriculotemporal nerve and its relationship to the middle meningeal artery. Anat Sci Int. 2015;90(4):216-21.

7. Murayama RA, Stuginski-Barbosa J, Moraes NP, Speciali JG. Toothache referred from auriculotemporal neuralgia: case report. Int Endod J. 2009;42(9):845-51.

8. Stuginski-Barbosa J, Murayama RA, Conti PC, Speciali JG. Refractory facial pain attributed to auriculotemporal neuralgia. J Headache Pain. 2012;13(5):415-7.

9. Levin M. Nerve Blocks in the treatment of headache. Neurotherapeutics. 2010;7(2):197-203.

10. The International Classification of Headache Disorders, $3^{\text {rd }}$ ed. (beta version). Cephalalgia. 2013;33(9):629-808.

11. Olesen J, Marie-Germaine B. The International Classification of Headache Disorders $2^{\text {nd }}$ ed. ICHD-ll. Headache. 2004;48(5):691-3
12. Pareja JA, Pareja J, Yangüela J. Nummular headache, trochleitis, supraorbital neuralgia, and other epicranial headaches and neuralgias: the epicranias. J Headache Pain. 2003;4(3):125-31.

13. Ansari H, Robertson CE, Lane JI, Viozzi CF, Garza I. Auriculotemporal neuralgia secondary to TMJ synovial cyst: A rare presentation of a rare entity. Headache. 2013;53(10):1662-5

14. Shimokawa T, Akita K, Sato T, Ru F, Yi SQ, Tanaka S. Penetration of muscles by branches of the mandibular nerve: a possible cause of neuropathy. Clin Anat. 2004;17(1):2-5.

15. Schmidt BL, Pogrel MA, Necoechea M, Kearns G. The distribution of the auriculotemporal nerve around the temporomandibular joint. Oral Surg Oral Med Oral Pathol Oral Radiol Endod. 1998;86(2):165-8.

16. Lemos L, Fontes R, Flores S, Oliveira P, Almeida A. Effectiveness of the association between carbamazepine and peripheral analgesic block with ropivacaine for the treatment of trigeminal neuralgia. J Pain Res. 2010;3:201-12.

1. Parte superior do formulário

17. Blumenfeld A, Ashkenazi A, Napchan U, Bender SD, Klein BC, Berliner R, et al Expert consensus recommendations for the performance of peripheral nerve blocks for headaches--a narrative review. Headache. 2013;53(3):437-46.

18. Di Stefano G, La Cesa S, Truini A, Cruccu G. Natural history and outcome of 200 outpatients with classical trigeminal neuralgia treated with carbamazepine or oxcarbazepine in a tertiary centre for neuropathic pain. J Headache Pain. 2014;15(1):34.

19. Cruccu G, Truini A. Refractory trigeminal neuralgia: non-surgical treatment options. CNS Drugs. 2013;27(2):91-6.

20. Yadav S, Mittal HC, Sachdeva A, Verma A, Dhupar V, Dhupar A. A retrospective study of 72 cases diagnosed with idiopathic trigeminal neuralgia in indian populace. J Clin Exp Dent. 2015;7(1):e40-4. 